\title{
Working party on the development of child psychotherapy services in the UK
}

\author{
Child and Adolescent Psychiatry Specialist Section
}

The Working Party was set up by the Child and Adolescent Section of the Royal College of Psychiatrists in response to the document Future of Psychotherapy Services(1) prepared by a working group of the Psychotherapy Section's Executive Committee because this report made no reference to the need for provision of services for children, young people and their families. It was proposed in March 1988, set up and started working in June 1988. This was at the same time as the Cleveland Enquiry report $^{(2)}$ was published. We now recognise and are aware that children who have been subjected to the whole range of abuse, sexual, physical and emotional, those experiencing neglect and other forms of deprivation, need help. Many other troubled children who have experienced disruption and disturbance, e.g. marital breakdown, multiple foster placements, also need help, as do seriously disturbed children and those who are physically and mentally handicapped.

\section{What is psychotherapy in child mental health?}

Psychotherapy is understood to mean the treatment of a patient or client with psychological or somatic disorders by non-physical means (or psychological means). In adults this will normally be through the medium of verbal communication. In very young children, play and activity are a predominant means of expression, with verbalisation increasingly used by older children, adolescents and young people. Psychotherapy can be used very loosely to describe all "talking" between therapist and patients or more formally to designate those exchanges which occur within a regular setting (time and place) using the relationship with the therapist as the major component of change.

Types of psychotherapy vary according to many parameters:

(a) Who is the patient

the individual child or parent

the marital couple

family

groups of children or parents

the professional organisation around the referred patient, e.g. school, nursery or professional system. (b) Psychological model behavioural model using learning theory cognitive model psychodynamic or psycho-analytic model systemic

(c) Duration of contact brief contact long term

(d) Frequency - there is a range which may include: single consultation of professional network family therapy at varying intervals once weekly individual or group sessions two to three weekly individual sessions (very rare).

\section{Terms of reference}

The Working Party has agreed to focus its attention on the current position and the development of psychodynamic psychotherapy for children and young people, in the UK. This can take the form of either individual help for children or young people, or group work with children or young people. It is essential to acknowledge that such work with children can never occur without the support of their parents or care givers and these people need help in their role as care giver and in sustaining the work with their child and so have to be included in our remit.

The Working Party considered the range of interventions possible: behavioural psychotherapy, family therapy, cognitive and Gestalt therapy. We decided not to consider these in detail. It may be thought necessary to do so at a later date. This group felt the task as defined was as much as they could undertake.

\section{Skills in psychodynamic understanding and treatment - the need}

Epidemiological studies of psychiatric disorder in children indicate a sizeable population with significant identifiable problems-Richman ${ }^{(3)}$, Leslie $^{(4)}$, Rutter et $a l^{(5)}$. Psychodynamic understanding provides a particular perspective when considering children and their families. It makes a specific 
contribution to the team's thinking when formulating ideas of appropriate interventions.

Psychodynamic psychotherapy as a treatment is particularly helpful when a child needs to make sense of things which are totally incomprehensible to him. It is not therefore so much related to a particular diagnosis or the severity of a disorder, much more to the context of the child; for example some cases of family breakdown, of divorce, child abuse, fostering and adoption problems or physical or mental handicap. In some cases rational approaches seem not to be able to assist these children and they remain confused and bewildered about apparently senseless change in their lives. A psychodynamic approach offers them the possibility of making sense of their experiences. It can help the child to assimilate emotionally personal experiences which are affecting his capacity to make and sustain mutually rewarding relationships. Often where there have been longstanding difficulties in relationships a psychodynamic approach can effect change ${ }^{(9)}$.

Health Service policy is to provide psychotherapy including psychodynamic psychotherapy based on psychoanalytic principles and to train people in several professions to carry it out ${ }^{(6)}$. In children's mental health facilities (e.g. child psychiatry, child guidance clinics and voluntary agencies) this work is carried out by suitably qualified child psychiatrists, child psychotherapists and other disciplines. However, there are no recommendations with regard to service provision or staffing levels.

\section{Surveys}

The Association of Child Psychotherapists (1988) ${ }^{(7)}$ have conducted a survey of child psychiatry and child guidance services. All services included in the Association of Child Psychology and Psychiatry handbook were contacted. They looked at:

(a) distribution of child psychotherapist (CP) posts

(b) the wish to establish or increase $\mathrm{CP}$ posts

(c) the contribution which CPs could make.

Some results are presented here (response rate $51 \%)(\mathrm{n}=269)$

(a) Distribution (Regional Health Authorities): This is extremely uneven with $79 \%$ of 174 established posts in the four health authorities of South East England. Five health authorities have no established posts. We are also aware that Scotland has only one child psychotherapist.

(b) Wish to establish or increase establishment of $C P$ posts:

The desired increase is 262 posts: there was no expressed wish to decrease posts in services where they were already established. This represents an increase of $150 \%$. (c) Contribution CPs could make to services:

Tasks for which child psychotherapists were required were identified by respondents as:

direct work with children

supervision of other professionals work with children

training in psychotherapy with children

This survey elicited a demand from multidisciplinary teams for the development of psychotherapy services for children and for training of other disciplines in this field.

The North West Regional Health Authority are in the process of conducting a survey of the further training requirements of workers already engaged in psychotherapy/play therapy/counselling with children: information is being sought from NHS, social services, education services and voluntary agencies. The results are not yet available.

\section{What is psychodynamic psychotherapy?}

Psychodynamic psychotherapy in child mental health is that model of therapy based on the theoretical constructs of psychoanalysis. Treatment of psychological or somatic disturbance is made by analysing the unconscious meaning of the words, the actions and imaginative life (dreams, phantasies and delusions) of the subject. In adults the method resides in the use of verbal "free associations", in children additionally in the use of free play or activity. Understanding of the unconscious is reached through interpretation of resistances, defences and the transference ${ }^{(8)}$. This model of therapy may be used for the treatment of child or parent. However, as a body of theory it informs thinking about and treating the family, groups of children or parents and professional organisations. Individual psychodynamic psychotherapy imposes a high commitment for both the therapist and the family, reflected in regularity and predictability of setting (time and place). Intensity will vary from one to five times a week; it can be brief say four to six sessions, for a year, or long-term open ended.

\section{Who does it?}

A description of who does psychotherapy depends on how it is defined. Various levels of skill are brought to bear on a child or adolescent suffering from emotional disturbance.

(a) Individuals whose skills have accrued through a specific psychotherapy training which requires supervision, practice and personal psychodynamic psychotherapy.

(b) Individuals who may have had some psychotherapy training and supervision as part of a generic training. 
(c) Individuals whose skills have accrued through experience with no formal training and who may or may not have sought supervision.

Few child and adolescent psychiatrists have a formal training in psychodynamic psychotherapy with children. Formal training in this area is largely undertaken by other disciplines who will then often change profession to that of child psychotherapist. In terms of long-term psychodynamic psychotherapy it is therefore largely only available in those parts of the country where there are training programmes, i.e. South East of England, or is practised by individuals who have gained experience through an adult psychodynamic training or have pieced together ad hoc training and supervision.

\section{The role of consultant child psychiatrists}

All child psychiatrists should in their training have some supervised experience of individual work with children, preferably a young child and an adolescent ${ }^{(10)}$. This should be for psychodynamic psychotherapy at least once weekly, preferably for an academic year minimum. Group work and work with care takers would also be an advantage. A period of young child observation would be a useful training experience prior to working with individual children. This would ensure all child psychiatrists were able to be with children. Communicating with children is a particular skill that needs to be learnt. Observing children and then working with them under supervision is the most effective training. There is an assumption that all child psychiatrists will have had seminars in child development and human growth and development to provide some theoretical underpinning for their experiential learning.

\section{Consultant child psychiatrists with a special interest}

Such consultants will have undertaken a recognised training in child psychodynamic psychotherapy. At present this is limited because of the location of most trainings in South East England. It is hoped that trainings will be established across the UK. These consultants will, as a minimum, have worked psychodynamically under supervision with a range of children once, and twice weekly, will have undertaken an infant observation seminar for one year, and will have attended psychodynamic theory seminars. It would be expected that they had worked with care takers, groups of children and institutions or agencies involved with children. This would ensure that they had experience of the application of psychodynamic ideas in a range of settings involving children and their care takers.

\section{Distribution of consultant child psychiatrists with a special interest or special responsibility}

There are a limited number of such child psychiatrists and at present it will seem more sensible to think of consultant child psychiatrists with a special responsibility. One task of these consultants would be to ensure that trainee child and adolescent psychiatrists all had sufficient experience in their general training. The second task would be to develop services to provide psychodynamic psychotherapy for the children that need it. There should be one such consultant per region and in some seriously disadvantaged areas, either within districts or where districts might link together, there could be one per group of child psychiatrists.

The aim should be to have sufficient consultant child psychiatrists with a psychodynamic psychotherapy qualification to have one per region, and preferably one per group of consultant child psychiatrists in districts where there is serious disadvantage.

\section{Implications for child psychiatrists}

There is a serious dilemma facing child and adolescent psychiatry in relation to the development of multidisciplinary work and this includes child psychotherapists. At the level of clinical work it is clear that the psychotherapeutic needs of children and their families across the country cannot be met by the services provided by child psychiatrists, nor should they be, since the child psychiatrists have many other tasks also to fulfil (11). The work of other disciplines is obviously needed to meet the service requirements. One way to meet these service requirements is to support the expansion of the child psychotherapy service.

At the level of clinical training of senior registrars, it is also clear that over the country as a whole there are insufficient consultants either able to (by virtue of their own training and interest) or with the time to provide supervision of psychotherapeutic communication with children (Appendix I). We consider that to be adequate, the training in psychotherapeutic work with children should be firmly based in a recognised theoretical framework and on the development of the particular skills associated with child psychotherapy which are well established. If they are not taught in this way, then it will be exceedingly difficult for the senior registrar, in his or her turn, to teach these skills to others. This does not mean that there should be a requirement for all senior registrars to embark on a formal psychotherapeutic training with personal psychotherapy, nor would it be appropriate to suggest this. But by contrast, occasional discussions about work with children cannot be considered to be a sufficient training for a future consultant. 
This raises the question about who should offer this training. It seems unlikely that there will ever be sufficiently trained and interested consultants to offer all the supervision required, although this might be a hoped for solution. Basic grade child psychotherapists in working as members of the multidisciplinary team would obviously be able to provide an important contribution to the knowledge and understanding of senior registrars. More senior child psychotherapists would provide the service with the possibility of more formal training extended to their own and other disciplines, in and associated with the clinical teams. This would result in expansion both of training and of service (see DHSS Personnel Memorandum 82/11 which states that supervision for other professionals should be at Senior grade or above $\left.^{(12)}\right)$. If carefully fostered, the appointment of more senior child psychotherapy staff could facilitate the development of the child psychiatric service and training of child psychiatrists.

\section{The role of other disciplines}

Other professionals with a psychodynamic psychotherapy qualification are working alongside child psychiatrists. They consist of:

(a) child psychotherapists

(b) other professionals who have had some modular input but have not completed a full training recognised by the ACP (Association of Child Psychotherapists).

In order to be in a position to support the development of child psychotherapy services and training in the UK, it is essential to provide a firm foundation of psychotherapeutic skills and understanding in the next generation of consultant child psychiatrists so that they will be capable of developing a joint interdisciplinary service based on mutual respect for the role and skills of each discipline.

\section{Role of child psychotherapists}

Of employed child psychotherapists, $90 \%$ work in the NHS (social services, education and voluntary sector employ remaining $10 \%$ ). The distribution of child psychotherapists, recently surveyed for $A C P^{(9)}$, shows more than half in child psychiatric settings in the community, $20 \%$ in hospital and $13 \%$ in training clinics; $15 \%$ are distributed throughout a variety of other settings. In these settings child psychotherapists offer treatment to severely disturbed and deprived children and adolescents. They offer less intensive treatment to children, adolescents and their parents. They undertake assessments. They offer training and supervision to trainee child psychotherapists and to other disciplines wishing to work with children, adolescents and their parents, using psychoanalytic concepts. They work consultatively in institutions involved with children, either providing input into case discussion or working with the staff group on the dynamics generated in the institution. Some psychotherapists work in paediatric settings, general, specialist or in special care baby units. Some work with children and young people in groups. Some psychotherapists are involved in research, some in teaching in academic settings.

Child psychotherapists are constantly exploring new ways of applying their skills to help children, e.g. severely disturbed and autistic children, severely deprived and abused children. Group work with children is also developing. In many District Health Authorities child psychotherapists function as managers within their own discipline and have a role in development and planning of mental health services at district or regional level.

Training of Child Psychotherapists in NHS Appendix II.

\section{Other professionals working therapeutically with children}

Many professionals are requesting some in-service training to enable them to carry out this part of their existing job better-social workers, teachers, occupational therapists, nurses, doctors, CMOs, GPs, paediatricians, child psychiatrists, speech therapists, special needs teachers, school counsellors, hospital play specialists. In NWRHA a multidisciplinary pilot course entitled 'Theory and Practice of Therapeutic Communication with Children' was started in 1987. There were 40 applicants for six available places. At the Tavistock Clinic a course on 'Therepeutic Communication with Children', run each year, had 50 applicants for 20 places for 1988-89.

\section{Future developments}

A priority must be the establishment of child psychodynamic psychotherapy trainings at strategic points in the UK; small trainings but with sufficient critical mass to sustain themselves and generate trainings for others, e.g. child psychiatrists, child psychotherapists, psychologists, etc.

Trainings could be in Birmingham, Manchester, Newcastle, Bristol and Edinburgh.

There are already embryonic developments in each of these centres which with encouragement could flourish. It will be essential that these trainings reflect the whole range of psychodynamic ideas and do not present a narrow view devoted only to a particular perspective. The range of ideas will ensure debate and discussion and enable trainees to use the full range of skills and understanding available now and as ideas evolve in the future. 
The College

\section{Creation of a new level of post-professional training}

Workers with children could be and should be encouraged to train for the Diploma in Therapeutic Communication with children, to meet the needs of children across the country. It would need endorsement by the Department of Health, the Department of Education and Science and the ADSS.

\section{A qualification in therapeutic communication with children and adolescents}

Many children are troubled or in distress and need someone to help them. Many are helped by parents, family friends, teachers etc. but many cannot talk to familiar adults, and many professionals in contact with children recognise the need to be able to listen and reflect back to the child in a non-direct or nonintrusive but helpful way. They also recognise that being trusted by a child demands considerable emotional resources from the adult if this trust is to be honoured and respected.

\section{Training}

Such training should consist of an observation seminar such as infant/young child and his family, a seminar in child development as part of human growth and development looking at current research findings, a clinical seminar for group supervision individual supervision of work with a child and group work with children.

Child psychiatrists with special responsibility for psychotherapy, child psychotherapists and others with a special skill in work with children would be suitable to provide this training.

\section{Role}

Completion of this training would enable workers in their own setting to provide a specialist resource. Children in trouble could be referred to them for their help. This would need the parent organisation to recognise the expertise held by the particular worker. They would need to be released from some of their previous duties to take on this specialist work.

Its organisation could be as a joint project between NHS, SSD and Education. If this training was sufficently available it could be a requirement for appointees to a child mental health team.

\section{Working together - how is this to be done?}

Professionals working at different levels of psychotherapeutic skill raise issues of co-operation and collaboration. Issues of seniority, responsibility and supervision will need to be resolved. (a) Consultant child psychiatrist with special responsibility for child psychotherapy or a special interest

It is suggested by the Working Party that the "core team" should include a consultant psychiatrist with a special interest in child psychotherapy. This consultant could head a multidisciplinary team or work in a multidisciplinary team headed by another consultant or colleague from another professional background. The consultant with a special interest will take on responsibility for "routine" child psychiatry work but will have as part of their remit the need to encourage the development of psychotherapy provision. One possibility would be for the consultant with a special responsibility to operate as a "consultant" to the core team and also to make and receive referrals from other psychiatric colleagues.

The consultant with special responsibility will, in addition, have a teaching and academic role which will require working together with other academic staff to plan and execute training programmes for many disciplines. The question of whether the consultant with special responsibility has an academic appointment should be addressed. Many such consultants appointed outside the London area will be expected to have a regional remit.

\section{(b) Consultant child psychotherapist (medical)}

This proposal was considered. The current position is that the Department of Health in negotiation with the Association of Child Psychotherapists recognise child psychotherapy as a para medical discipline and that it is not at present possible for a medical consultant to be appointed as a child psychotherapist. Any wish to change this would require negotiations with Department of Health and ACP.

Child and adolescent psychotherapists are currently in negotiation with the Department of Health about their salary scales and gradings and are negotiating a level of consultant child psychotherapist. This would be for a person who has not had a medical training, who is a trained psychotherapist and is to be appointed at a very senior level. An alternative to be considered would be to have medical consultant psychotherapists (children). Such a consultant could make a contribution both to training child psychiatrists and provide an input in adult psychotherapy training service. The increased understanding of children would be of benefit directly in understanding adults, and in understanding the effects of disturbance in adults who are parents, on their children. They could also provide some service and links to facilitate referral of children of adult patients. Negotiations would be required with the Psychotherapy Section of the Royal College of Psychiatrists. 


\section{(c) Non medical child psychotherapist}

This category of post has been created for those professionals from non medical disciplines who have received intensive training in psychotherapy. The pattern of working of these psychotherapists would probably differ considerably from that of the consultant psychiatrist with special responsibility, in that the broader psychiatrist managerial and clinical responsibility would not fall to the non medical psychotherapist.

These psychotherapists would work in a multidisciplinary team as a full member of that team, accepting and making referrals as well as providing a specialised psychotherapeutic view of cases. The psychotherapists would also act independently and have a high level of clinical autonomy.

\section{(d) Workers with a Diploma or equivalent}

This refers to members of many disciplines who have received some additional training in therapeutic communication with children. These individuals would continue to operate as social workers, occupational therapists, nurses, etc., but their additional skill would be recognised in the kind of cases that they worked with, and hopefully by financial reward.

The hierarchy of line management and accountability in each discipline would not be affected by this extra skill and clinical responsibility would operate as at present within the multidisciplinary team.

\section{Recommendations}

The Committee wished it to be noted that this is a preliminary document. In order to carry it forward, there would need to be discussions with other professional organisations in the public, private and voluntary sector, involved in work with children.

However, following further discussions in the Executive Committee, there are some specific recommendations to be made:

(1) Consultant posts in child and adolescent psychiatry

It is recommended that appointments committees should be advised of the need to consider making appointments of consultant child psychiatrists who have a specific interest and training in psychodynamic psychotherapy with children and adolescents, so that they can be available to take additional special responsibility for training, and supervision, and service provision. Such appointments need to be sufficiently distributed across regions and linked to regional training schemes. This may be achieved by appointing at least one per region but where there are groups of consultant child psychiatrists, such an appointment could be made across neighbouring districts. This kind of appointment strategy needs to be considered (a) in order to ensure that senior registrars receive good training in psychotherapeutic communication with children from psychiatrists as well as from child psychotherapists and (b) in order to ensure the maintenance of a psychodynamically oriented psychiatric contribution to services for children.

\section{(2) General issues}

(a) The Committee acknowledges that the availability of psychotherapeutic treatment for children and adolescents in the NHS needs to be expanded.

(b) Consideration should be given to the establishment of psychodynamic child psychotherapy trainings at key points around the country. Such centres would provide a focus for training, supervision and consultation. This would be of value to all disciplines including child psychiatry, as a focus for multidisciplinary training in a similar way to other trainings such as family therapy.

(c) Qualification courses in therapeutic communication with children should be established for the range of professionals working with children. This could include senior registrars in child and adolescent psychiatry.

(d) To facilitate working together the professional relationship between child and adolescent psychiatrists and psychotherapists needs ongoing consideration.

\section{Membership:}

Drs J. Trowell (Chair), C. Lindsey, C. Kaplan, J. Robinson and A. Sutton; with contributions from Mrs S. Ramsden, Principal Child Psychotherapist.

\section{References}

1. Future of Psychotherapy Services EFCC 353/87

2. Report of the Inquiry into Child Abuse in Cleveland 1987

3. Richman, N., Stephenson, J. \& Graham, P. (1975) Prevalence of behaviour problems in three year old children: an epidemiological study in a London Borough, J. Child Psychol. Psychiat., 16, 222-287.

4. LesLIE, S. A. (1974) Psychiatric disorder in the young adolescents of an industrial town. British Journal of Psychiatry, 125, 113-124.

5. Rutter, M., Graham, P., Chadwick, O. \& Yule, W. (1976) Adolescent turmoil: fact or fiction? J. Child Psychol. Psychiat., 17, 35-56.

6. Tavistock and Portman Clinics' Review 1985. A report by NHS Management Services.

7. Survey by ACP 1988 of Child and Family Mental Health Clinics of Provision of Child Psychotherapists. 
8. Leplanche and Pontales-The Language of Psychoanalysts 1973.

9. Making the case for Child Psychotherapy 1988.

10. Psychotherapy training for Senior Registrars in Child and Adolescent Psychiatry.

11. Role of Child Psychiatrists. S. Wolkind, A. Cox, 1989.

12. DHSS Personnel Memorandum 82/11.
13. A short history of the Association of Child Psychotherapists 1984.

14. A Child Psychotherapy Trainees Guide 1988.

Approved by Council

June 1990

\section{Appendix I}

\section{Senior registrar training in child and adolescent psychiatry}

\section{Child psychotherapy}

\section{Current JCHPT guidelines}

The following list details the experience available in child psychotherapy in senior registrar training schemes in the UK and the Republic of Ireland. It is taken from JCHPT (CAPSAC) reports where reference is made to the availability of this experience and its supervision.

Scheme 1: Experience of family therapy and individual psychotherapy available. Good supervision of this is included in the academic programme.

Scheme 2: Good provision for supervised individual psychotherapy and family therapy.

Scheme 3: There is an emphasis on psychodynamic types of treatment. Strong in the teaching of individual psychotherapy and family therapy.

Scheme 4: There is little emphasis on dynamic individual or group psychotherapy. Child psychotherapists are available for supervision in quarter of the total number of placements but not in the two main centres. In general a lack of psychotherapy supervision and some instances where senior registrars were supervising registrars' psychotheray without receiving supervision of this experience.

Scheme 5: One full-time child psychotherapist available who provides good supervision. Some supervised behavioural therapy also available. Trainees may also participate in courses at the Institute of Family Therapy. Longterm child psychotherapy is available but supervised from outside the scheme.
Scheme 6: There is only limited psychotherapy training available and this is weighted towards the psychodynamic model. Supervision generally available from outside the scheme.

Scheme 7: Psychotherapy is available in school settings. Experience available with child psychotherapists from another region. Opportunities for personnel supervision from a psychotherapist from within the scheme.

Scheme 8: Supervision available from a child psychotherapist. Live supervision is given of family therapy.

Scheme 9: A child psychotherapist gives supervision. This is also provided by other individuals skilled in child psychotherapy, e.g. occupational therapist.

Scheme 10: Behaviour therapy available, supervised by the principal clinical psychologist.

Scheme 11: No child psychotherapist in the region Behaviour therapy supervised by a principal psychologist.

Scheme 12: Little child psychotherapy or group therapy. Fortnightly psychotherapy seminars. Regular family therapy workshops using live supervision.

Scheme 13: Family therapy supervised by a consultant child and adolescent psychiatrist. Individual psychotherapy supervision focusses on the trainees personal development. Insufficient supervision of individual child psychotherapy.

Scheme 14: Individual psychotherapy is carried out by the senior registrars and supervised by a psychotherapist. Behaviour therapy is supervised by clinical psychologists. 
Scheme 15: No long-term psychotherapy is available. There is a heavy emphasis on family therapy. A child psychotherapist is available to provide supervision.

Scheme 16: Psychotherapy supervision is timetabled in all placements.

Scheme 17: Family, individual and group therapy are available in all placements. Some behaviour therapy available. Good supervision for individual psychotherapy.

Scheme 18: Emphasis on family therapy in one placement. Little individual psychotherapy experience available in half of the scheme. Supervision of psychotherapy is carried out on a seminar basis by buying in time from a local child psychotherapist.

Scheme 19: Family therapy and individual therapy are strengths of the scheme. Supervision of this is available from a principal clinical psychologist.

Scheme 20: Opportunities for dynamic psychotherapy supervised by a consultant psychotherapist.

Scheme 21: Problems with psychotherapy supervision because of commitments of the newly appointed consultant designated to undertake this role.

Scheme 22: Several different forms of psychotherapy available with opportunities for long-term psychotherapy. Good supervision.

Scheme 23: One hour per week of intensive supervision of individual and family therapy.

Scheme 24: The various types of psychotherapy are not uniformly available so trainees can miss certain experiences.

Scheme 25: No long-term individual psychotherapy. Behaviour therapy and group therapy available and supervised by non-medical staff.

Scheme 26: A range of psychotherapies available.

Scheme 27: A wide range of psychotherapies available. Supervision of individual child psychotherapy problematic but good supervision of behaviour therapy.

Scheme 28: Good supervision of behaviour therapy from a clinical psychologist. Individual psychotherapy for children supervised by consultant child and adolescent psychiatrists.

\section{Appendix II}

\section{Training of child psychotherapists in NHS}

Child psychotherapy is a post graduate profession. Its members originate in the associated professions including psychology, social work, education, medicine, nursing, speech therapy. All child psychotherapists possess:

(1) an Honours degree, or the recognised equivalent of a degree, followed by an appropriate postgraduate course. All candidates should have attended a course covering the study of human relations and child development

(2) pre-training experience in work with children of varying ages

(3) personal suitability.

The Association of Child Psychotherapists, founded in 1949 , is responsible for:

(1) granting recognition to new schools of training

(2) monitoring standards in existing schools of training

(3) suspension of recognition of existing trainings.

All trainings work in line with principles established by the ACP and contained in 'Outline for Training Courses' (June 1987 revision).
There are four training schools at present (1989), ${ }^{13,14}$ all London based and the firm prospect of the establishment of a Scottish based training school:

(i) Tavistock Clinic - training in psychoanalytic psychotherapy in NHS. Established 1949. Status: NHS.

(ii) The Anna Freud Centre for Psycho-Analytic Study (AFC) and Treatment of Children. Training in child analysis. Founded in 1949. Status: Registered charity

(iii) Society of Analytical Psychology (SAP). Established 1949. Training in child psychotherapy established in 1973. Status: private.

(iv) British Association of Psychotherapists (BAP). Established 1951. Training in Child Psychotherapy established in 1982. Status: private.

\section{Common features of training}

(1) Length: minimum four years full time.

(2) Personal analysis: minimum three times weekly throughout training. 
(3) Clinical work: three analytic cases under supervision, minimum thee times weekly, including male and female and from three age groups - pre-latency, latency, adolescence. Non-intensive cases, under supervision. Work with parents under supervision. Assessment.

Some experience in brief counselling and/or family work.

(4) Training in infant observation, child development.

(5) Academic training in theory and technique.

\section{Differences between training \\ (1) Size \\ Tavistock: 10 on average per year}

AFC: 5 or 6 on average, every other year

SAP: between 1 and 3 each year

BAP: 5 or 8 on average, every other year, capacity 12

(2) Status

Tavistock only NHS based funded

AFC - a charity with few training grants for selected students

BAP and SAP - private students self-financing

(3) Theoretical bases

Tavistock: Kleinian and post-Kleinian

AFC: Freudian and contemporary Freudian

SAP: Jungian

BAP: Independent

Theoretical differences are reflected in teaching and orientation of analysts and supervisors used by four training schools.

Psychiatric Bulletin (1991), 15, 55

\title{
The North East Division Trainees' Day 1990
}

\author{
Denise Riordan and Andrew Clark, Collegiate Trainees' Committee Representatives, \\ North East Division
}

The 1990 North East Division Trainees' Day was held in Newcastle upon Tyne on 19 April 1990 , and was attended by 26 trainees, mainly from the Northern region.

The morning session concentrated on the theme of 'Training in Teaching', and was opened by Professor Sims, College Dean, who emphasised the importance of teaching in clinical work. He discussed how the skills needed for this are gained and developed, and talked about the activities of the College in this respect. It is an area currently being considered by both the College Central Approval Panel and the Joint Committee on Higher Psychiatric Training. He stressed the need for the profession to be both self questioning and research orientated, while not losing sight of its primary duty to patients.

Alan Millward (Director of In-Service Education at Newcastle University) continued on the theme of being self questioning, and suggested there is often a discrepancy between theory and practice in dayto-day professional life. He used a team building exercise as a way of showing how useful it is to stand back and observe one's actions, so as to learn from them, and to help bring theory and practice into closer harmony.

Dr Ian McKeith (Senior Lecturer at Newcastle University) brought the morning session to a close with a pragmatic discussion about how to teach others. He emphasised the importance of recognising the needs of an audience, while at the same time choosing a topic in which one is interested, so as to be more likely to give a confident and lively presentation. He also emphasised the value of constructive feedback in helping one develop teaching skills.

In the afternoon the topic of community psychiatry was addressed by Dr Jan Scott (Senior Lecturer at Newcastle University) and Dr John Nehaul (Consultant Psychiatrist at St James' Hospital, Leeds). The benefits and pitfalls of working as a member of a multidisciplinary team in a variety of settings were discussed, with the focus upon the needs of trainees. The relationship between clinicians and management was explored in depth, with particular reference to the importance of clinicians as leaders and motivators in a team, taking an active role in decision making and resource allocation.

Both sessions provoked vigorous discussion, with training issues very much to the fore. Trainees felt it would be valuable to follow up a person with chronic mental illness over a long period, so as to gain more insight into how community and hospital services work together in the interest of patients. 